\title{
O (não)dito da AIDS no cotidiano de transição da infância para a adolescência
}

\author{
The (un)said about AIDS in the quotidian transition from childhood to the adolescence
}

Lo (no)dicho del SIDA en el cotidiano de transición de la infancia para la adolescencia

\section{Cristiane Cardoso de Paula', Ivone Evangelista Cabral", Ivis Emilia de Oliveira Souza"}

' Universidade Federal de Santa Maria (UFSM/RS), Departamento de Enfermagem. Santa Maria-RS, Brasil.

"Universidade Federal do Rio de Janeiro, Escola de Enfermagem Anna Nery (UFRJ/EEAN), Departamento de Enfermagem Materno-Infantil. Rio de Janeiro-RJ, Brasil.

Submissão: 8/6/2011 Aprovação: 20/10/2011

\section{RESUMO}

Crianças infectadas por transmissão vertical do HIV transitam da infância para adolescência, e pouco se sabe sobre seu dia a dia. O objetivo foi compreender o (não)dito da AIDS em seu cotidiano. Após aprovação pelos Comitês de Ética em Pesquisa de três hospitais do Rio de Janeiro, entrevistou-se onze meninos(as) de 12 a 14 anos, que conheciam seu diagnóstico. A hermenêutica heideggeriana desvelou que o ser-adolescendo adquiriu a doença da mãe; ficou triste por ter familiares doentes; relembrou da revelação diagnóstica e do preconceito que os silenciavam, projetando-se como ser-de-possibilidades num movimento existencial. O cuidado ao ser-adolescendo precisa integrar as dimensões biológica, clínica, sociocultural, ética, política, assistencial e existencial.

Descritores: Saúde da criança; Saúde do adolescente; Enfermagem Pediátrica; Síndrome de Imunodeficiência Adquirida.

\begin{abstract}
HIV children infected by vertical transmission are crossing from childhood to adolescence, however, we do not know how they are caring for themselves during those transitional age. The objective was to understand the (un)said about AIDS in their quotidian. After approval by the Research Ethics Committee of three hospitals in Rio de Janeiro, the interview was conducted with eleven boys/girls from 12-14 years old, who knew their diagnosis. The Heideggerian hermeneutics unveiled that the adolescent-being knows that the disease was acquired by his/her mother; he/she was said that his/her relatives are sick; he/she reminds when the diagnosis was disclosure, and its relation to prejudice. He/she projects him/her as a being-of-possibilities inside an existential movement. One concludes that the care for adolescent-being needs to integrate the biological, clinical, socio-cultural, ethical, political, and existential dimensions.
\end{abstract}

Key words: Adolescent health; Child health; Pediatric Nursing; Acquired Immunodeficiency Syndrome.

\section{RESUMEN}

Niños infectados por transmisión vertical del VIH transitan de la infancia para la adolescencia, y poco se sabe de su cotidiano. El estudio tuvo como objetivo comprender lo (no) dicho del SIDA en su cotidiano. Tras la aprobación por los Comités de Ética en Investigación de tres hospitales de Rio de Janeiro, se entrevistó 11 niños de 12-14 años, que conocían su diagnóstico. La hermenéutica heideggeriana dio a conocer que el ser adoleciendo sabe que adquirió la enfermedad de la madre; es triste tener familiares enfermos; recuerda de la revelación diagnóstica y del prejuicio que los silencian. Se proyecta como ser de posibilidades en un movimiento existencial. El cuidado al ser adoleciendo precisa integrar las dimensiones biológica, clínica, socio-cultural, ética, política y asistencial y existencial.

Palabras clave: Salud del niño; Salud del adolescente; Enfermería Pediátrica; Síndrome de Inmunodeficiencia Adquirida. 


\section{INTRODUÇÃO}

Com o investimento crescente para dar conta do agente etiológico da Síndrome da Imunodeficiência Adquirida (AIDS), na busca da garantia da sobrevivência, um grupo de crianças com AIDS por transmissão vertical não morreu. Venceu a etapa da infância, adentrando em uma nova fase do desenvolvimento humano. Esse grupo é conhecido como a primeira geração que nasceu infectada pelo Vírus da Imunodeficiência Humana (HIV) e está adolescendo ${ }^{(1-5)}$.

Observa-se que o foco da atenção está direcionado mais à clínica do adoecimento do que, propriamente, à criança doente em transição para a adolescência, em sua dimensão existencial. As produções disponíveis sobre a população de adolescentes tratam mais sobre a prevenção da infecção do que propriamente do cotidiano dos que foram infectados ${ }^{(6)}$.

As vivências do adolescente que tem AIDS mostram que ele transita por essa fase do desenvolvimento com características comuns aos adolescentes que não têm a infecção. Relaciona-se com familiares e amigos e mantém atividades do dia a dia e lazer. Em que as transformações físicas e psicossociais somam-se às necessidades específicas da condição sorológica, como a descoberta do diagnóstico, às repercussões da doença no seu dia a dia devido ao cotidiano terapêutico e às situações de preconceito e discriminação ${ }^{(7)}$. Cuidar de si é algo que ele tem de fazer e precisa querer fazer ${ }^{(8)}$.

A problemática delineada trata da AIDS no interior da família, cuja convivência social é mediada pelo silêncio e o segredo, na ótica dos profissionais de saúde e familiares ${ }^{(9-13)}$. Assim, tem-se a necessidade de investigar, com as crianças infectadas pelo HIV por transmissão vertical em transição da infância para a adolescência, o seu cotidiano no cuidado de si, com o objetivo de compreender o (não)dito da AIDS no cotidiano do ser-adolescendo.

A dimensão existencial do cuidado de si de crianças em transição do desenvolvimento humano da infância para a adolescência permanece um desafio para os profissionais de saúde em geral, e de enfermagem em particular, por constituir um novo grupo no contexto social brasileiro. Esse novo grupo apresenta uma demanda de necessidade especial de saúde das crianças que têm AIDS, qual seja: a dependência da tecnologia medicamentosa. Portanto, são inseridas no grupo de crianças com necessidades especiais de saúde (CRIANES), as quais requerem: uso contínuo de medicamentos para sobreviver; serviços de suporte emocional/comportamental, elevada frequência na unidade de saúde; acompanhamento por vários profissionais de saúde, de diferentes especialidades; expertise no cuidado profissional e familial; e educação em saúde contínua ${ }^{(3)}$.

Essas necessidades especiais de saúde determinam desafios do cuidar diante da demanda de atenção especializada a outras referentes à sua fase de crescimento e desenvolvimento. Justifica-se o presente estudo pela necessidade de ampliar a literatura disponível, cujo foco centra-se mais nas dimensões clínico-epidemiológicas e socioantropológicas da problemática do HIV/AIDS na infância e na adolescência ${ }^{(14-16)}$.

\section{MÉTODO}

Investigação de natureza qualitativa, com abordagem fenomenológica e referencial teórico-metodológico de Martin Heidegger ${ }^{(17-18)}$. Teve como sujeitos de pesquisa 11 meninos(as) infectados(as) por transmissão vertical do HIV. Os critérios de inclusão foram: faixa etária de 12-14 anos; conhecer o seu diagnóstico, não estarem institucionalizados. Dos 11 sujeitos, dois eram órfãos maternos, um era órfão paterno e três eram órfãos paternos e maternos, sendo cuidados por membros da família consanguínea de primeiro grau. Os outros cinco estavam sob os cuidados de ambos os pais. O número de sujeitos não foi determinado previamente, visto que a etapa de campo mostrou o quantitativo de entrevistas necessárias para responder ao objetivo da pesquisa ${ }^{(19)}$.

O cenário da pesquisa contemplou três hospitais universitários (HU), que são referência para atendimento de crianças e de adolescentes que têm HIV/AIDS, no Rio de Janeiro. A etapa de campo foi desenvolvida de fevereiro a setembro de 2007, após aprovação e autorização dos Comitês de Ética em Pesquisa (Protocolos EEAN/UFRJ 096/06; IPPMG/UFRJ 09/07; HUGG/UNIRIO 36/07). Os familiares assinaram o Termo de Consentimento Livre e Esclarecido e os 11 meninos(as) assinaram o Termo de Assentimento.

Para produção dos dados empíricos foi utilizada a entrevista fenomenológica ${ }^{(19)}$. Essa modalidade de acesso aos participantes possibilita um movimento de compreensão do vivido do ser humano, tal como se apresenta na sua vivência cotidiana. Como modo de acesso ao ser, a entrevista é desenvolvida como um encontro, singularmente estabelecido entre o sujeito pesquisador e cada participante pesquisado. O encontro aconteceu após a consulta de acompanhamento permanente de saúde, em uma sala do ambulatório hospitalar, o que garantiu privacidade aos depoentes, conforme previamente acordado com a equipe de cada HU. A entrevista foi mediada pela empatia e intersubjetividade, valendo-se da redução de pressupostos. Exigiu do pesquisador um posicionamento de descentramento de si, para se direcionar intencionalmente à compreensão dos adolescentes.

Durante o encontro, o pesquisador precisou: estar atento aos modos de se mostrar do participante entrevistado; captar o dito e o não dito; observar as outras formas de discurso: o silenciado, os gestos, as reticências e as pausas; e respeitar o espaço e tempo do outro. Essa posição de abertura do pesquisador ao outro possibilitou aprimorar progressivamente a condução da entrevista. A entrevista se iniciou pela questão orientadora: Conte-me como está sendo virar adolescente. A questão "Como é o seu dia a dia tendo essa doença?" foi aplicada somente quando o depoente falava da sua condição sorológica. Utilizou-se a palavra "doença", pois a AIDS foi mencionada dessa forma nas entrevistas, sendo referenciada, mas não nominada. No decorrer da entrevista a pesquisadora formulou questões empáticas, a fim de evitar induzir respostas, mas destacando questões expressas pelos adolescentes que precisavam ser aprofundadas para melhor compreensão dos possíveis significados apontados. Para encerrar a entrevista, era desenvolvido um feedback, perguntando se o adolescente gostaria de acrescentar algo e agradecendo sua disposição para esse encontro. 
Os depoimentos foram gravados mediante consentimento e a transcrição das entrevistas se deu conforme a fala original, na qual a pesquisadora apontou os silêncios e as expressões corporais observadas durante o encontro. As entrevistas foram codificadas com a letra $C$ de "criança", seguidas dos números de 1 a 11 .

A partir da leitura e escuta atentiva dos depoimentos, foram desenvolvidos os dois momentos metódicos: a compreensão vaga e mediana (dimensão ôntica) e a compreensão interpretativa (dimensão ontológica) ${ }^{(17)}$.

A compreensão vaga e mediana consiste em captar os significados como modos de ser. Primeiramente, foram explicitados os fatos (dimensão ôntica) que se mostraram, diretamente e na maioria das vezes, no cotidiano do ser-adolescendo. Foi desenvolvida a busca das estruturas essenciais (significantes), por meio do exercício de distinção entre o que se manifestou como ocasional/acidental e como essencial (significados que apontam para como o fenômeno é). As estruturas essenciais constituíram as Unidades de Significação (US), a partir das quais se desenvolveu o discurso fenomenológico do seguinte modo: descrevendo os significados de estar adolescendo com AIDS e demonstrando a compreensão do ser-adolescendo com AIDS acerca de seu cotidiano.

A compreensão interpretativa teve as USs como fio condutor da hermenêutica. Os significados desvelaram alguns sentidos presentes no cotidiano de estar adolescendo e ter AIDS, os quais foram interpretados segundo o referencial teórico de Heidegger $^{(17)}$. Assim, foram desveladas facetas do fenômeno (dimensão ontológica) - que não se mostram diretamente, nem em sua totalidade -, as quais indicaram possibilidades de cuidado de si e de assistência em saúde.

\section{RESULTADOS E DISCUSSÃO}

Ao dar voz, na entrevista fenomenológica, ao ser em transição da infância para a adolescência, inicialmente ele se apresenta como alguém que sabe que tem a doença da mãe, que é ruim ter familiares doentes ou que já morreram. A vida se inicia marcada pela herança da AIDS, pelas perdas e pela orfandade.

O ser-adolescendo herdou o vírus da mãe e do pai. Adquiriu durante a gravidez, parto ou amamentação, e acredita que sua mãe recusou-se a fazer o exame de seguimento, aceitar o diagnóstico ou seguir o tratamento; ou o tratamento não foi eficiente para evitar a transmissão vertical. Desse modo, o ser-adolescendo tem consciência da gênese da doença em sua vida a partir dos pais.

Eu peguei essa doença da minha mãe. Eu tenho mais dois irmãos, só que eles não pegaram [...] quando ela tava grávida de mim, não queria fazer [o exame], porque já tinha feito e dado negativo [...] quando ela fez [o exame], ela não quis aceitar [o resultado positivo] [silêncio] não se conformou com isso [...] Ela pegou do meu pai [...] aí eu nasci [...] (C2)

O ser-adolescendo acreditava que seu problema era no coração ou que precisa tomar vitaminas. Mas, situações no dia a dia que o faziam pensar e comparar - como o fato de ir sempre ao médico -, como sendo uma particularidade sua, pois isso não acontecia com seus colegas.

Não sabia quando era pequena [...] mas eu pensava: meus colegas não vão para o médico, só eu! O que é que eu tenho? [silêncio] (C2)

Antes eu achava que tomava vitaminas [...] (C4)

Antes eu achava que era só problema de coração[...] (C6)

O seu existir é marcado também pelas circunstâncias ao relembrar como soube da sua doença. Desde o momento da revelação se estabeleceu um acordo de silêncio, pois lhe disseram que não poderia contar para ninguém por causa do preconceito. O sentimento foi de tristeza e vergonha.

Seu diagnóstico é conhecido por poucos. Apenas algumas pessoas de sua família, do hospital e, em algumas situações, o diretor da escola ou o professor(a). A família diz que não deve contar para ninguém, e ele não conta, selando com a família um acordo de silêncio sobre a condição.

A minha família fala para mim não falar nada para ninguém, só quando eu tiver casada já, na hora do sexo [...] (C2)

Ela falou para eu não contar para ninguém, só para gente particular no hospital [...] (C4)

Minha vó conversou com a diretora, então ela sabe por que eu tenho que vir no hospital [...] (C5)

Eu não conto para ninguém. [silêncio] Meus amigos não sabem, e nem na escola. Pra que contar? Não gosto, não preciso ficar falando [...] (C10)

Às vezes, ele compartilha sua situação com alguém especial. Acha que, se contar para alguém, as pessoas não vão querer chegar perto dele. Foi alertado sobre o preconceito e passou a vivenciá-lo. Mas, acredita que, somente ao olhá-lo, as pessoas não percebem que ele tem essa doença.

[...] ninguém [da família] nunca me rejeitou, nunca falou que eu sou diferente porque tenho isso [...] se ninguém me rejeita, por que eu vou ficar me rejeitando à toa? [...] eu tinha vergonha que tinha HIV, eu me achava diferente das outras pessoas [...] teve um tempo que eu conheci uma garota, ela é muito especial para mim, eu cheguei para ela e falei o que eu tinha e pensei que ela ia virar a cara para mim, e isso não aconteceu [...] ninguém fala que eu tenho isso, na rua quem olha não sabe [...] (C3)

Esse quadro existencial, por sua vez, cria nesse ser-adolescendo uma identidade existencial muito singular daqueles que foram infectados por transmissão vertical. Nessa identidade existencial, o ser-adolescendo significa o seu Eu, compreendendo-se como alguém que vive um cotidiano, tendo um 
vírus dentro do seu corpo e uma vida normal. Compreende que o emagrecimento e a dor física dos familiares doentes justifica o uso contínuo do remédio, ao mesmo tempo em que gera, para si, tristeza e choro.

É que ela [a mãe] tá doente [silêncio], tem dores, precisa tomar remédios, vir ao hospital. [silêncio, e sem levantar os olhos diz:] É ruim ter minha mãe doente [...] (C1)

Quando eu vejo minha irmã ruim, me dá uma dor [...] vontade de chorar, e eu não podia, então eu me faço de durona [...] [silêncio] (C3)

Se o pai ou a mãe já morreu, isso aconteceu logo depois de seu nascimento ou quando ainda era criança. O ser-adolescendo vive num mundo inventado para ocultar o vírus.

Tem seis anos que minha mãe faleceu de HIV [...] ela pegou do meu pai, que também faleceu [...] meus colegas me perguntavam: "Ela morreu de quê?". Aí eu invento [...] às vezes eu não gosto nem de lembrar [...] [silêncio, olha para baixo e chora] (C2)

Na minha família ninguém mais tem, só eu e minha mãe [...] ela morreu oito meses depois que eu nasci. Eu não penso muito nisso [...] [silêncio] (C8)

Por tudo isso, o ser-adolescendo sente-se desamparado pela ausência da mãe e/ou do pai no seu cotidiano.

[...] é muito difícil [silêncio e volta a olhar para mim chorando] [...] minha mãe não tá aqui comigo [silêncio] nem meu pai [...] tu quer ter uma mãe por perto [silêncio] pra te amparar [...] fiquei revoltada, com depressão[...] eu tenho a minha tia, mas eu sou muito sozinha [...] às vezes é difícil encarar isso tudo, essa doença [...] (C2)

A situação existencial marcada pelo movimento da infância para a adolescência desperta sua curiosidade sobre seu problema de saúde. O ser-adolescendo relembra que a descoberta da doença aconteceu quando alguém da família contou, por vezes, com a ajuda de um profissional. Foi explicado que, desde o nascimento, possuía o mesmo vírus da sua mãe; daí a necessidade de ir ao hospital e tomar remédios.

Teve uma época que eu queria saber mais sobre isso, aí eu fui perguntar à minha mãe o que eu tinha, e ela começou a chorar e me explicou: "Não foi culpa minha, eu não queria que você tivesse esse vírus.". [...] aquilo me bateu. (C3)

Eu soube esse ano aqui no hospital, com a psicóloga [silêncio] é que a minha mãe não conseguia me dizer, aí acho que ela ajudou [...] (C11)

Antes da revelação, ainda criança, desconfiava de algo, pois já ouvira sobre a doença, na escola, na televisão, nas consultas ou tinha lido nos papéis do hospital. Cercado pelo não-dizer da doença, o ser-adolescendo percebeu algo diferente dentro de si.

Quando soube, eu fiquei muito triste, porque é chato ter essa doença [...] [silêncio] (C4)

Minha vó que me contou, eu já sabia que ela ia falar [...] (C5)

Eu já sabia, porque eu prestava atenção nos papéis, ficava prestando atenção nas consultas, nas informações, eu ouvia coisas na televisão, na escola. [silêncio] Ela [a mãe] nunca falou sobre isso, mas eu sabia [...] (C11)

O ser-adolescendo compreende que o vírus é parte do seu existir 'normal', não é considerado uma fatalidade. O remédio pode revelar a doença, que é segredo em seu existir, que está guardada no silêncio da família e dos profissionais de saúde.

[...] é normal [pausa na fala] porque, assim, o professor falou comigo, que também tem outros lá na escola que têm problema, que a mãe passou para o filho [...] (C2)

[ter HIV] [...] não é assim uma fatalidade [silêncio] porque, se fosse, eu já estaria em cima da cama chorando que nem uma margarida [...] (C3)

É ruim ter esse vírus, não é uma pessoa normal [...] eu me sinto normal, o que não é normal é ter que ficar tomando esses remédios [...] (C10)

\section{DISCUSSÃO}

O movimento existencial do ser-adolescendo se mostra nos modos-de-ser no cotidiano: da inautenticidade para a autenticidade. A inautenticidade foi evidenciada no modo da angústia imprópria e da ambiguidade. A autenticidade foi evidenciada no modo da angústia própria do ser-de-possibilidades.

A angústia imprópria se revela pelo medo do ser-adolescendo diante do enfrentamento da herança da AIDS, marcada pelas perdas e pela orfandade. $\mathrm{O}$ fenômeno do temor pode ser considerado segundo três perspectivas: o que se teme, o que temer e pelo que se teme. O que se teme, o "temível", é sempre um ente que vem ao encontro dentro do mundo e que está simplesmente dado $^{(17)}$. Para o ser-adolescendo, o temível é a própria AIDS.

$\mathrm{O}$ que se teme possui um caráter de ameaça, portanto, trata-se de determinar fenomenalmente o que é temível? ${ }^{(17)}$. Sobre a AIDS, o ser-adolescendo tem consciência da gênese dessa doença em sua vida a partir dos pais, uma doença até então sem cura, que, em alguns casos, determinou a morte do pai e/ou mãe.

Percebe-se na ameaça da AIDS o modo conjuntural de dano, que sempre se mostra dentro de um contexto em que o ser-adolescendo reconhece seu cotidiano tendo um vírus. A doença traz em si a determinação da região dada e do estranho que dela provêm, ambos conhecidos ${ }^{(17)}$. A região dada é o que já se sabe da AIDS, pelo que o ser-adolescendo já ouviu falar na 
escola, na mídia, no serviço de saúde. O estranho são as experiências da AIDS na família. Mesmo conhecendo as repercussões clínicas e sociais na vida de seus pais, o ser-adolescendo ainda não vivenciou tais repercussões, apesar de saber o que pode vir a acontecer em sua vida. A exemplo do preconceito, da relação sexual, da gestação, inclusive da morte.

$\mathrm{O}$ danoso ameaça, pois pode acontecer ou não. Diante disso, o ser-adolescendo vive num mundo inventado para ocultar o vírus e onde se sente desamparado pela ausência da mãe e/ou do pai no seu cotidiano. A AIDS se irradia nas relações do ser-adolescendo consigo e com-os-outros, e seus raios apresentam caráter de ameaça que pode concretizar-se naquilo que anuncia-se como dano, ou pode nunca acontecer. Mesmo na possibilidade do dano ausentar-se da vivência do ser-adolescendo, isso não diminui nem resolve o temor, ao contrário, o constitui ${ }^{(17)}$.

Estar em perigo é a ameaça do ser e estar junto ao que é temível, em que a AIDS pode concretizar o dano estando mais do que no sangue, por isso o vírus não é considerado uma fatalidade, mas o remédio pode revelar a doença. Portanto, o remédio o torna diferente, e não o vírus.

Além do temer-algo, Heidegger compreende que há o temor-por, quando o temor estende-se a outros - no caso, membros da família do ser-adolescendo - que demonstram medo-em-lugar-do-outro, sem Ihe retirar o temor. A família tem medo do preconceito, por isso assume o não dito de ter AIDS e recomenda o acordo de silêncio.

A família também tem medo das consequências da AIDS na saúde do ser-adolescendo se ele não tomar os remédios como deve. Então, assume um cuidado como solicitude substitutiva-dominadora, que, ao estar-junto, toma o lugar do outro num movimento de saltar sobre ele, colocando-se na posição de cuidar ${ }^{(17)}$. A família assume o encargo que é do outro: o cuidar de si. Como ser-criança estava dominado, tornando-se dependente dos cuidados familiares.

Os momentos constitutivos de todo fenômeno de temor podem variar. Nessas variações, surgem diferentes possibilidades do temer: o pavor, o horror e o terror ${ }^{(17)}$.

$\mathrm{Na}$ medida em que uma ameaça que ainda não se tornou concreta, mas que a qualquer momento pode acontecer, subitamente se abate sobre o ser-no-mundo da ocupação, o temor se transforma em pavor ${ }^{(17)}$. Portanto, o pavor manifesta-se quando a ameaça conhecida e familiar se abate sobre o ser de modo súbito. O ser-adolescendo já sabia da AIDS, no entanto, quando a família lhe revela o diagnóstico, sente-se surpreso e apavorado.

Se, ao contrário, o que ameaça possuir o caráter de algo totalmente não familiar, o temor transforma-se em horror ${ }^{(17)}$. Sobre a AIDS, eles sabem que a transmissão do vírus acontece por relação sexual ou uso de drogas; no entanto, consigo (ser-adolescendo), sua infecção foi por transmissão vertical do HIV. Então, aquilo que Ihe vem ao encontro não é conhecido e ele sente-se horrorizado.

E somente quando o que ameaça vem ao encontro com caráter de horror, possuindo ao mesmo tempo o caráter de pavor, o temor torna-se, então, terror ${ }^{(17)}$. O terror manifesta-se quando a ameaça tem caráter não familiar e súbito. Quando o ser-adolescendo se vê diante da possibilidade de namorar e de ter que revelar seu diagnóstico a outro adolescente, sente-se aterrorizado.
Neste cotidiano da AIDS na família e em si se estabelecem o dito e o não dito, que apontam para duas condições existenciais características do humano: autenticidade e inautenticidade.

O ser-adolescendo mostra-se na autenticidade quando: na infância começa a refletir sobre a necessidade de manter um acompanhamento de saúde, diferente da maioria das crianças; isso os leva, na adolescência, à curiosidade de saber mais e a questionamentos que suscitam a revelação do diagnóstico, e os diferentes sentimentos que emergem. A autenticidade se refere a ser fiel ao próprio eu, ser sua própria pessoa, ser quem se é, agir por conta própria, pensar por si mesmo ${ }^{(17)}$.

No entanto, as circunstâncias do dia a dia assistencial, ao mesmo tempo em que apresentam possibilidades, impõem restrições no que diz respeito à AIDS. Um dos modos de reagir, como mostram os adolescentes, está em se manter no anonimato, no silêncio de seu diagnóstico, determinado pelo que se toma por bom, e não o determinado por seu próprio eu. Em que poucas pessoas sabem e não falam sobre isso - quando a família diz para não contar para ninguém devido ao preconceito, o ser-adolescendo assim o faz. Portanto, a inautenticidade está em fazer aquilo que os outros querem que seja feito, seguir a determinação dos outros ${ }^{(17)}$, transferindo sua decisão seja à família, aos profissionais da saúde, ou à sociedade.

Quando o ser-adolescendo se compreende como normal apesar do vírus, contenta-se com a repetição do que já foi dito, acreditando que as coisas são como são, pois assim se fala delas, o que evidencia a falta de solidez de compreensão e constitui o falatório(17). O falatório constitui o modo da compreensão cotidiana em que o ser cai no palavreado e passa adiante a notícia, não com a intenção de dizer coisas sobre o mundo, mas de romper o silêncio e manter a comunicação(17).

Na convivência cotidiana, tanto o que é acessível a todo mundo quanto aquilo de que todo mundo pode dizer qualquer coisa vêm igualmente ao encontro. Então, não há como distinguir, na compreensão autêntica, o que se abre do que não se abre ${ }^{(17)}$. Assim, o ser-adolescendo mostra-se no modo-de-ser da ambiguidade, quando diz que é adolescente como todos, mas que cada pessoa é diferente da outra; ou que é normal ter o vírus, mas ter que tomar remédios não é normal. Então, tudo parece ter sido compreendido, quando não o foi. Essa ambiguidade não se estende apenas ao mundo, mas, também, à convivência como tal e até mesmo ao ser da presença para consigo mesmo ${ }^{(17)}$.

\section{CONCLUSÕES}

No cotidiano, o ser-adolescendo experiencia a AIDS na família e vivencia a AIDS em si. Sendo assim, para que o cuidar em saúde seja integral e possa respeitar as singularidades, é preciso que os profissionais de saúde que cuidam do ser-adolescendo o compreendam em sua tríplice constituição existencial: historicidade, temporalidade e espacialidade.

No intuito de conhecer essa tríplice constituição da existencialidade, a Enfermagem precisa estar disposta e disponível a encontrar-se com o ser-adolescendo. O encontro precisa ser mediado pela empatia e inter-subjetividade, em que o 
profisional de enfermagem mostre-se comprometido em escutar, respeitar e ajudar o ser-adolescendo. Essa ajuda vai além da atenção às suas necessidades biológicas do adolescer e da fragilidade clínica da AIDS, mas busca contemplar o modo como ele se sente, suas vivências, seus limites e possibilidades diante daquilo que precisa e (não)quer.

O serviço de saúde pode ser um lugar privilegiado para a construção desse vínculo interpessoal, de abertura, respeito e comprometimento, em que os seres de cuidado, seja o profissional, o ser-adolescendo, seja o familiar, possam se conhecer, compreender e cuidar-se. No entanto, o cenário institucional está determinado por normas e rotinas prescritivas que atendem as demandas do adoecimento, mas não do viver. Mas, o serviço de saúde é o lugar que o ser-adolescendo frequenta periodicamente e a longo prazo; desde seu nascimento ou infância e por tempo indeterminado, já que trata-se de uma doença até então sem cura. Portanto, um espaço com potencial para o investimento da atenção à dimensão existencial, articulada à biológico-clínica.

Para isso, as consultas precisam atentar aos protocolos de atendimento e ao ser-adolescendo que ali se encontra para ser cuidado. Esse ser tem o cotidiano das necessidades especiais de saúde como parte da vivência do adolescer e do adoecer, que não podem ser aferidas nos exames, nem tratadas com a tecnologia medicamentosa.

A atenção a essas vivências demanda o investimento de um tempo que não é cronológico, mas existencial. Ou seja, não pode ser controlado pelo relógio, pela agenda de consultas ou pela rotina institucional, mas pelo encontro em que ambos os seres do cuidado precisam estar dispostos-para compartilhar essa relação, que ultrapassa o planejamento da assistência e é mediado pelo ser-com.

Sendo-com, o profissional de enfermagem pode buscar compreender a historicidade do ser-adolescendo, marcada pela AIDS na família e em si, por vezes, por perdas e orfandade. Durante a infância, a criança, que tem AIDS por transmissão vertical não conhece exatamente a doença que possui, acredita que tem algum outro problema de saúde e por isso precisa ir ao hospital e tomar remédios. Esse conhecimento limitado de sua condição sorológica é mantido pela família, que pactua com os profissionais esse silêncio, ambos considerando a imaturidade cognitiva e emocional da criança.

Diante da transição para a adolescência, a família e os profissionais passam a perceber a necessidade de revelar o diagnóstico, tanto pelo desabrochar da sexualidade quanto pela adesão ao tratamento. Precisam falar abertamente com o ser-adolescendo, sem silêncios ou segredos, para que ele possa comprometer-se conscientemente com o seu cuidado, com os conhecimentos e ferramentas necessários para proteger a sua saúde e a de outros.

O ser-adolescendo revela que, mesmo antes de lhe contarem que tem AIDS, ele já sabia de diversas formas, mas manteve o silêncio pois ninguém falava disso. Assim, o profissional de enfermagem deve ficar atento para os modos com que o ser-adolescendo demonstra (não) saber de sua doença, pois pode construir um canal para que ele rompa com o não dito, mostrando-se disposto a falar, mesmo antes de sua família tomar a decisão da revelação do diagnóstico. Buscando evitar que o ser-adolescendo seja silenciado quando evidenciar necessidade e desejo de falar. Esse pacto de silêncio ou silenciamento acontece entre a família, mas não deve acontecer no serviço de saúde. O espaço do serviço de saúde deve ser constitutivo de diálogo, sempre que o ser-adolescendo demonstrar disponibilidade-para falar sobre sua saúde/doença. Pela experiência que tem da doença de seus pais, o ser-adolescendo teme adoecer e morrer. Esse medo evidencia a necessidade do diálogo que possibilite vencer essa angústia imprópria que o paraliza e se estabelece como limite aparentemente intransponível, pois, se tem a mesma doença da mãe, e se ela morreu, isso também lhe acontecerá.

No entanto, com ajuda de alguém que o encoraje a ir além desse temor e possibilite um olhar às suas potencialidades, o ser-adolescendo pode desenvolver um movimento de angústia própria. (Re)conhecendo-se como ser-de-possibilidades, percebe que, apesar da facticidade da AIDS, tem um futuro que não está determinado pelo vivido de seus pais, mas depende de diversas questões, inclusive da decisão de assumir-se naquilo que quer, precisa e pode fazer por si-mesmo.

Portanto, o profissional de enfermagem pode ajudá-lo no cuidar de si, como um campo de possibilidades para além do vivido pelos familiares. O cuidar de si também está interligado à temporalidade do ser-adolescendo, pois o momento de transição para adolescência não é o tempo determinador dessa capacidade. Aquilo que se constrói-junto e que proporciona conhecimento e instrumentos é que, paulatinamente, possibilitará o desenvolvimento da autonomia nas atitudes e comportamentos para assumir o cuidado de si.

\section{REFERÊNCIAS}

1. Dourado I, Veras MASM, Barreira D, Brito AM. Tendência da epidemia da AIDS no Brasil após a terapia anti-retroviral. Rev. Saúde Públ. 2006;40(supl):9-17.

2. Schaurich D, Coelho DF, Motta MGC. A cronicidade no processo saúde-doença: repensando a epidemia da AIDS após os anti-retrovirais. Rev. enferm. UERJ. 2006; 14(3):455-62.
3. Gomes AMT, Cabral IE. O cuidado medicamentoso à criança com HIV: desafios e dilemas de familiares cuidadores. Rev Bras Enferm. 2009; 62(2):252-7.

4. França I Junior, Doring M, Stella IM. Crianças órfãs e vulneráveis pelo HIV no Brasil: onde estamos e para onde vamos? Rev. Saúde Públ. 2006; 40(supl):23-30. 
5. Schaurich D, Medeiros HMF, Motta MGC. Vulnerabilidades no viver de crianças com AIDS. Rev. enferm. UERJ. 2007;15(2):284-90.

6. Ribeiro AC, Padoin SMM, Paula CC, Santos ÉÉP. Teens who may become infected with hiv and adolescents who have sida: narrative review. Revista de Enfermagem UFPE on line [Internet]. 2010 [citado 20 jan 2010]; 4(spe):23743. Disponível em: http://www.ufpe.br/revistaenfermagem/index.php/revista/article/view/1028/pdf_105.

7. Paula CC, Cabral IE, Souza IEO. O cotidiano do ser-adolescendo com AIDS: movimento ou momento existencial? Esc. Anna Nery. 2009;13(3):632-9.

8. Paula CC, Cabral IE, Souza IEO. O cotidiano de crianças infectadas pelo HIV no adolescer: compromissos e possibilidades do cuidado de si. DST. J Bras Doenças Sex Transm. 2008; 20(3-4):173-9.

9. Sousa AS, Kantorski LP, Bielemann VLM. A AIDS no interior da família: percepção, silêncio e segredo na convivência social. Acta Sci Health Sci 2004;26(1):1-9.

10. Marques HHS, Silva NG, Gutierrez PL, Lacerda R, Ayres JRCM, DellaNegra $M$ et al. A revelação do diagnóstico na perspectiva dos adolescentes vivendo com HIV/ AIDS e seus pais e educadores. Cad. Saúde Pública. 2006;22(3):619-29.

11. Wiener L, Mellins CA, Marhefka S, Battles HB. Disclosure of an HIV diagnosis to children: history, current research, and future directions. J Dev Behav Pediatr. 2007;28(2):155-66.

12. Schaurich D, Motta MGC. Relações entre o familiar e a criança com AIDS: compreensões à luz de Martin Buber. Rev. Gaúcha Enferm. 2008;29(2):254-61.

13. Butler AM, Williams PL, Howland LC, Storm D, Hutton $\mathrm{N}$, Seage GR. Impact of disclosure of HIV infection on health-related quality of life among children and adolescents with HIV infection. Pediatrics. 2009;123(3):935-43.

14. Cruz EF. Infâncias, adolescências e AIDS. Educação em Revista (UFMG) 2007;(46):363-84.

15. Lima AAA, Pedro ENR. Crescendo com HIV/AIDS: estudo com adolescentes portadoras de HIV/AIDS e suas cuidadoras-familiares. Rev. Latino-Am. Enfermagem [internet]. 2008 Mai-Jun [citado 20 jan 2010]; 16(3). Disponível em: http://www.scielo.br/pdf/rlae/v16n3/pt_03.pdf

16. Spinardi JR, Machado JKC, Sant'Anna MJC, Passarelli MLB, Coates V. Adolescer com HIV: saber, conhecer e conviver. Adolesc \& Saúde. 2008; 5(2):7-14.

17. Heidegger M. Ser e Tempo. Petrópolis (RJ): Vozes; 2002. Parte I.

18. Silva JMO, Lopes RLM, Diniz NMF. Fenomenologia. Rev Bras Enferm. 2008;61(2):254-7.

19. Carvalho AS. Metodologia da entrevista: uma abordagem fenomenológica. Rio de Janeiro (RJ): Agir; 1991. 